\title{
CUSTO DE PRODUÇÃO DE OVOS EM SISTEMA CAIPIRA NA REGIÃO DE ILHA SOLTEIRA (SP)
}

Felipe de Lima Silva', Diana Suckeveris², Amanda da Lapa Silva², Nathália Raquel Menegante Néri ${ }^{2}$, Maria Aparecida Anselmo Tarsitano ${ }^{3}$, Antonio Carlos de Laurentiz ${ }^{4}$

${ }^{1}$ Graduado em Zootecnia - FE/UNESP Ilha Solteira. ${ }^{2}$ Graduado em Zootecnia FE/UNESP Ilha Solteira. ${ }^{3}$ Docente do Departamento de Fitotecnia, Tecnologia de Alimentos e Sócio-Economia - FE/UNESP Ilha Solteira. ${ }^{4}$ Docente do Departamento de Biologia e Zootecnia - FE/UNESP Ilha Solteira.

RESUMO: O baixo custo dos produtos oriundos da indústria avícola tem tornado o setor cada vez mais atrativo devido ao grande aumento de consumo dos produtos originados deste. Este trabalho tem por objetivo avaliar a qualidade da produção de ovos em sistema caipira, com a finalidade de proporcionar uma renda extra para os pequenos produtores. A utilização dos materiais presentes na propriedade ajudou a diminuir o custo da produção de ovos. As aves utilizadas serão da linhagem EMBRAPA 051 num número de 104 aves (96 matrizes e 8 machos) que devem ser alojados em um galpão artesanal de $100 \mathrm{~m}^{2}$. Os indicadores econômicos utilizados foram os propostos por Martin et al. O custo operacional efetivo para a produção de ovos caipiras foi de $\mathrm{R} \$ 4.565,90$ representando $93,29 \%$ do COT. Dos itens que compõem o COT, o mais significativo é ração que soma quase $85 \%$ do COE e $79,12 \%$ do COT. A atividade apresenta lucratividade mais não pode funcionar como única fonte de renda do produtor e sempre que possivel este deve buscar formas de valorizar seu produto.

Palavras-chave: postura, renda, colonial, alternativa.

\section{COST OF EGG PRODUCTION IN THE REGION OF HILLBILLY SYSTEM ILHA SOLTEIRA(SP)}

ABSTRACT: The low cost of poultry products from the industry sector has become increasingly attractive due to the large increase in consumption of products derived from this. This study aims to evaluate the quality of egg production in hillbilly system, in order to provide extra income for small producers. The use of the materials present in the property to help lower the cost of production of eggs. The birds will be used strain EMBRAPA 051 a number of 104 birds ( 96 arrays and 8 male) to be housed in a warehouse of $100 \mathrm{~m}^{2}$ craft. The economic indicators used were those proposed by Martin et al. The operational cost for the production of eggs hicks was $\mathrm{R} \$ 4,565.90$ representing $93.29 \%$ of total operating cost. Of the items that make up the total operating cost, the most significant is that diet adds nearly $85 \%$ of the operational cost and $79.12 \%$ of total operating cost. The activity shows more profitability cannot function as the sole source of income of the producer and where possible this should seek ways to enhance your product.

Key words: posture, income, colonial, alternative.

\section{INTRODUÇÃO}

Os produtos oriundos da indústria avícola, carne de frango e ovos, são, atualmente, as principais fontes de proteína de origem animal de mais baixo custo na alimentação humana, e muito útil na indústria de transformação (LOT et al., 2005). Segundo 
Braga et al. (2005) o ovo de galinha é um dos alimentos naturais mais completos, pois fornece ao homem um balanço de nutrientes indispensáveis à sua nutrição.

O Brasil é o sétimo maior produtor de ovos do mundo, atrás dentre outros, da China, Estados Unidos, México, Japão, informa os dados do Departamento de Agricultura dos Estados Unidos. O consumo de ovos, atualmente, gira em torno de 140 unidades per capita no Brasil, quantidade baixa quando comparada com outros países, como, por exemplo, o México, com um consumo de 374 ovos per capita ao ano (AVISITE, 2008). Conforme dados do Instituto Brasileiro de Geografia e Estatística (IBGE), no ano de 2010, a produção de ovos chegou a 2.460.369 mil dúzias, correspondendo a aproximadamente 29 milhões de unidades, aumento de 4,2\% sobre o ano de 2009.

A cadeia produtiva de ovos no Brasil se caracteriza pela produção de ovos para consumo tanto "in natura", quanto industrializados. A produção é feita predominantemente no sistema de criação em gaiolas, com grandes produtores que utilizam adequação climática e automação das instalações. Segundo Moreira (2008), essa produção de pequenos e médios produtores é um dos segmentos da avicultura alternativa, que tem se mostrado um mercado consumidor oferecendo um produto diferenciado.

Outro importante fato a ser observado nesse tipo de produção é a capacidade de integração de criação de galinhas com outras atividades agrícolas, agroindustriais, extrativistas, pecuárias, que são costumeiramente desenvolvidas pelo agricultor familiar, o que resulta na agregação de valor e maior remuneração por produto acabado (SAGRILO, 2002).

A produção de aves no sistema "caipira", para que seja viável, deverá ser direcionada para a alimentação alternativa (MAlA, 1997), à base de milho e complementada com concentrados específicos, devem ser ofertados também alimentos alternativos encontrados com facilidade e a um custo minimo na propriedade, como capins, folhas verdes, feno de mandioca e leucena, sementes em geral, insetos, minhocas, etc., Do ponto de vista econômico, a alimentação é um fator de grande importância não somente porque dela depende um bom desempenho produtivo das aves, mas, sobretudo, porque representa boa parte dos custos da atividade, estima-se que o custo de produção do quilograma do ovo, a ração é o item que entra em maior proporção, perfazendo 65 a $70 \%$ do custo total (BRAGA, 2005).

Baseado nesse contexto o presente trabalho teve por objetivo, avaliar a qualidade da produção de ovos em sistema caipira, com a finalidade de proporcionar uma renda extra para os pequenos produtores de Ilha Solteira (SP) e região.

\section{MATERIALE MÉTODOS}

\section{Fonte de Dados e Localização:}

O estudo econômico foi realizado no município de llha Solteira, no noroeste paulista, com extensão territorial de $659 \mathrm{~km}^{2}$. Encontra-se geograficamente nas coordenadas $51^{\circ} 06^{\prime} 35^{\prime \prime} \mathrm{W}$ de longitude e $20^{\circ}$ $38^{\prime} 44^{\prime \prime} \mathrm{S}$ de latitude, numa altitude de $330 \mathrm{~m}$. O local é classificado como tropical chuvoso de bosque, sendo clima de llha Solteira é marcado por chuvas de verão e estiagem no inverno. Os meses mais quentes concentramse no início do ano de janeiro a abril e, o frio ocorre no mês de junho.

\section{Sistema de Produção de Ovos:}

Segundo Barbosa et al. (2011) o Sistema de Criação de Galinhas Caipiras, ao simultaneamente resgata a tradição de criação de galinhas caipiras, e tem como objetivo o aumento do padrão econômico da agricultura familiar, melhorando a qualidade e aumentando a quantidade da produção. Sabe-se que esse tipo de sistema minimiza os danos ao meio ambiente, adotando adequações necessárias a cada ecossistema onde é implantado, seja com relação às suas instalações e equipamentos, seja na forma de alimentar ou de medicar alternativamente as 
aves (BARBOSA et al., 2004).

Os técnicos que deram apoio à pesquisa consideram que pequenos produtores têm poucos recursos em suas propriedades para a criação de galinha caipira, portanto para a implantação do sistema buscamos trabalhar com materiais já existentes nas propriedades para diminuir o custo de produção. Podemos usar materiais como palha, canos, baldes de plástico, caixas de papelão, madeira, folha de bananeira, bambu e estacas entre outros materiais que são uteis para a construção dos piquetes, ninhos, bebedouros e comedouros que serão improvisados, por exemplo.

Figueiredo et al. (2011) cita que o fornecimento de água deve ser em abundância para as futuras galinhas poedeiras, limpa, pura, fresca com temperatura adequada para os animais e isenta de microrganismos. Faz parte do manejo sanitário a limpeza dos bebedouros. Nesse sistema de criação é possivel usar equipamentos diferentes para bebedouros, como o uso de canos cortados ao meio, por exemplo:

A alimentação alternativa (capim, hortaliças, frutas e tubérculos) somente deverá ser oferecida após a quarta semana de idade e não ultrapassar $25 \%$ do total da alimentação diária consumida (FIGUEIREDO et al., 2001). Sabe-se que galinhas caipiras podem se alimentar somente de milho e proteína animal (insetos) encontrada durante o ato de ciscar, contudo, elas não obterão um resultado tão promissor, por isso é aconselhável oferecer ração para aumentar os índices de produtividade. Embora o milho atue diretamente na gema tornando-a mais nutritiva e a alimentação verde auxilie no sistema digestivo das aves caipiras, a ração comercial é indicada para que esta ave tenha um melhor desenvolvimento.

No manejo alimentar das aves não é aconselhável a utilização de fontes proteicas de origem animal (farinhas). A dieta adequada deve ser composta de ingredientes exclusivamente de origem vegetal, sendo proibido o uso de remédios para o crescimento, antibióticos e pigmentos na ração no caso desse sistema de criação. A ração deve ser adquirida de fornecedor idôneo. Quando houver condições de fabricação de uma boa ração na propriedade, uma opção é fabricá-la com aquisição do núcleo (FIGUEIREDO et al., 2011), como mostra o exemplo de ração de postura oferecido por Gessulli (1999), misturando-se $10 \%$ do núcleo de postura para a fase de produção com $60 \%$ de milho moído, mais $22 \%$ de farelo de soja 45 e $8 \%$ de calcário com $38 \%$ de cálcio.

A alimentação representa cerca de $70 \%$ do custo da produção das aves, principalmente porque as matérias-primas são largamente usadas tanto para criação de aves altamente tecnificadas quanto para o consumo humano. O que se deve fazer é buscar fontes alternativas de alimentos, principalmente energéticos e proteicos, como também de formulações que atendam às necessidades qualitativas e econômicas de produção da galinha caipira (BARBOSA et al., 2011).

$\mathrm{Na}$ substituição por alimentos alternativos podemos usar alimentos produzidos na região e que muitas vezes são descartados como rama de mandioca, farelo de mandioca, talo de couve, folha de bananeira, farelo de trigo, entre outros alimentos. Por fim, a ração deve combinar alimentos energéticos, proteicos, minerais e aditivos (verificar quais são permitidos para esse sistema de criação).

No período de produção, a rotina diária no aviário deve contemplar limpeza dos bebedouros, retirada das aves mortas ou feridas e coleta frequente dos ovos, utilizandose bandejas higienizadas. Providenciar sistematicamente o destino dos resíduos da produção (aves mortas, estercos, restos de ovos e embalagens). As instalações devem estar desinfectadas e com vazio sanitário maior do que 21 dias. Os ovos devem ser coletados a cada duas horas para evitar a contaminação com sujidades e classificados conforme as exigências do mercado, dando destino diferente e imediato aos ovos quebrados e com casca mole (FIGUEIREDO etal., 2011). 
Sabe-se que a produção de ovos por cabeça de galinha gira em torno de 1 ovo/dia, mais neste caso por a dieta ser alternativa, a produção será em menor quantidade, sendo assim é necessário obter um plantel de aves grande o suficiente para que a ocorrência de possíveis problemas não afetem a produção.

Apesar das galinhas caipiras botarem poucos ovos, é de valia dizer que as coloniais são excelentes chocadeiras não só dos próprios ovos. Elas possuem um instinto maternal aguçado protegendo tanto os ovos quanto a cria.

As aves adquiridas devem estar vacinadas contra doenças como a doença de Marek e variola aviária e serem revacinadas ainda quando pintainhas aos 20 dias de idade e apresentar potencial produtivo comprovado geneticamente. A vacina contra as doenças de Newcastle, bronquite infecciosa e Gumboro devem ter sido aplicadas também. Já o controle de endo e ectoparasitas devem ser efetuados com base no monitoramento periódico do lote, sendo que para a coccidiose, através de vacinação que ocorreu no primeiro dia de vida da ave (FIGUEIREDO etal., 2006).

Os piquetes devem ser feitos próximos ao local coberto para a postura. Para pastejo são utilizadas as forrageiras que suportam a bicada e o ciscar das galinhas. Segundo os técnicos, as gramineas estoloniferas com caules rasteiros são aconselháveis para esse tipo de comportamento, dentre elas estão o Capim Quicuiu, Capim Coast Cross, Capim Tifton, Grama Estrela Africana, Grama Seda.

Esse sistema consiste na criação de galinhas caipiras semiextensivo, de aves melhoradas da linhagem EMBRAPA 051 de alta produtividade e elevada rusticidade. A produção estima um número de 104 aves (16 meses de idade), sendo 96 matrizes e 8 machos que devem ser alojados em um galpão artesanal de $100 \mathrm{~m}^{2}(10,0 \times 10,0 \mathrm{~m})$, dividido em 8 piquetes de $6,25 \mathrm{~m}^{2}(2,5 \times 2,5 \mathrm{~m})$ para pastejo e postura. A reposição dos lotes deverá ocorrer a cada 12 meses. Segundo a média de valores da região de llha Solteira, o lote de aves será obtido pelo valor de
$\mathrm{R} \$ 10,00$ /ave.

Cada piquete é composto por 13 animais, sendo 12 fêmeas e 1 macho, calculase 5 aves $/ \mathrm{m}^{2}$, contendo 2 ninhos e bebedouros e comedouros que serão feitos de cano PVC, cada um com $1,00 \mathrm{~m}$ de comprimento para atender todos os animais. Cada animal em média consome $85 \mathrm{~g}$ de ração, já que a alimentação será reforçada com ingestão de pastos e pequenos insetos no pasto de criação, e duas vezes o valor de água, que deve ser fornecida três vezes ao dia através da mão de obra familiar. A ração será adquirida pronta com custo média de $R \$ 1,20 / \mathrm{kg}$. O vermifugo é calculado um sachê para cada 12 litros de água.

A estrutura do galpão artesanal será revestida de cerca de arame galvanizado e telhas sem cimento amianto, para evitar a entrada de água e a cobertura dos ninhos. Iremos utilizar o arame no perimetro da estrutura e também na divisão dos piquetes $(10,5 \mathrm{~cm} \times 10,5 \mathrm{~cm})$ totalizando $75 \mathrm{~m}$. Para a confecção do telhado será necessário $50 \mathrm{~m}^{2}$ de telhado de brasilit, 1 pacote com 50 peças de pregos e 6 barrotes $(4,0 \mathrm{~m}$ de comprimento).

O piso é revestido de Tifton-85 que servirá também para o pastejo, a alimentação será baseada no fornecimento de ração diária, essa adquirida pronta em lojas de produtos agropecuários. O piso adubado, com adubo orgânico, uma vez ao ano na época das chuvas para manutenção da gramínea.

A produção de ovos em um período de 60 semanas é de aproximadamente 249-257. Com produção máxima estimada de $94-96 \%$. Cada embalagem é vendida pelo valor de 2,50 a dúzia. Considerando os dados anteriores, as poedeiras irão produzir no total cerca de 90/ovos/dia. Essa quantidade de ovos ao ano irá proporcionar uma produção de 2700 dúzias/ano.

O descarte das aves será feito após 12 meses de postura dentro do sistema de produção, estas serão vendidas para corte pelo valor de $\mathrm{R} \$ 15,00$ /ave. Através do retorno obtido será possível formar um novo plantel para dar continuidade à atividade.

O manejo será inteiramente realizado 
por mão-de-obra familiar, entre eles alimentação; retirada, embalagem e venda dos ovos até pequenos reparos necessários durante a criação.

\section{Análise Econômica:}

Os indicadores de análise de resultados de rentabilidade empregados no trabalhoforam os definidos em Martin et al. (1998):

a) Receita Bruta (RB): é a receita esperada para uma produção por unidade de área, para um preço de venda pré-definido ou efetivamente recebido:

$R B=\operatorname{Pr} \times P u$

Onde, $\operatorname{Pr}=$ produção de dúzias de ovos;

$\mathrm{Pu}=$ preço unitário da dúzia de ovos;

b) Lucro operacional (LO) ou receita liquida $(R L)$ : é a diferença entre a receita bruta e o custo operacional por unidade de área. Esse indicador mede a lucratividade da atividade em curto prazo.

$L O=R B($ ReceitaBnta $)-\cot ($ CustoOperacionalTotal $)$

c) Índice de lucratividade (IL): é a relação entre o lucro operacional e a receita bruta, em percentagem

$$
I L=(L O \div R B) \times 100
$$

d) Ponto de nivelamento (PN): determina qual é a produção mínima necessária da dúzia de ovos para cobrir o custo operacional total, dado o preço unitário de venda da dúzia de ovos

$$
P N=\cot \div P u
$$

\section{RESULTADOS E DISCUSSÃO}

O custo total de implantação do projeto de aves caipiras em sistema semiextensivo em uma área de $100 \mathrm{~m}^{2}$ foi de $\mathrm{R} \$ 2.730,26$, deste total cerca de $48 \%$ referese às despesa com o galpão seguido pelas despesas com aquisição das aves com $38 \%$ (Tabela 1). Esse sistema foi baseado na produção em baixo custo com materiais e equipamentos de valores acessiveis, os quais são possiveis substituir por produtos já existentes na propriedade, diminuindo ainda mais o custo de implantação da atividade. As depreciações com o galpão, piquetes e instalaçes foram de $\mathrm{R} \$ 100,00 / a n o$. .

Tabela 1. Investimentos necessários para a implantação do galpão artesanal e dos piquetes para produção de ovos de galinhas caipiras em sistema semiextensivo, na região de llha Solteira - SP.

\begin{tabular}{l|l|l|l|l}
\hline DESCRIÇÃo & Unidade & Quantidade & $\begin{array}{l}\text { Valor Unitário } \\
\text { (R\$) }\end{array}$ & $\begin{array}{l}\text { Valor Total } \\
\text { (R\$) }\end{array}$ \\
\hline 1. Galpão & & & & \\
\hline Cerca de arame galvanizado & m & 40 & 3,85 & 154,00 \\
\hline Mourōes de Eucalipto & unid. & 7 & 4,50 & 31,50 \\
\hline Portão de alambrado & unid. & 1 & 500,00 & 500,00 \\
\hline Telha de Brasilit & $\mathrm{m}^{2}$ & 50 & 9,55 & 477,50 \\
\hline Parafusos para telha & pct. & 1 & 10,20 & 10,20 \\
\hline Barrote & unid. & 6 & 25,0 & 150,00 \\
\hline Sub total & & & 553,10 & 1323,20 \\
\hline 2. Piquetes & & & & \\
\hline Cerca de arame qalvanizado & m & 35 & 3,85 & 134,75 \\
\hline Cano de PVC & 6 m & 2 & 88,66 & 177,32 \\
\hline Cola de PVC & unid. & 1 & 6,99 & 6,99 \\
\hline Ninhos & unid. & 16 & 3,00 & 48,00 \\
\hline Sub total & & & 102,50 & 367,06 \\
\hline Total de Investimentos & unid. & & & $1.690,26$ \\
\hline Aves (16 semanas) & unid. & 104 & 10,00 & $1.040,00$ \\
\hline Total & & & & $\mathbf{2 . 7 3 0 , 2 6}$ \\
\hline Depreciações & & & & $100,00 / a n o$ \\
\hline $\begin{array}{l}\text { Depreciação do galpão, } \\
\text { piquetes e instalaçōes }\end{array}$ & & & & \\
\hline
\end{tabular}


$\mathrm{Na}$ Tabela 2 estão detalhados os coeficientes técnicos e os preços obtidos para produção de ovos caipira. O custo operacional efetivo para a produção de ovos caipiras foi de $R \$ 4.565,90$ representando $93,29 \%$ do COT. Dos itens que compõem o custo operacional total, o mais significativo é ração que soma quase $85 \%$ do COE (Custo Operacional Efetivo) e $79,12 \%$ do COT. Este resultado coloca em evidência o rigor técnico requerido na alimentação das aves, reforça a importância que o produtor precisa exercer na gestão de seus custos, principalmente na hora que for adquirir a ração, se preocupando também com a sua composição e qualidade.
O produtor precisa criar formas para reduzir estes custos, com alternativas de menor custo, considerando que o sistema é semiextensivo. Braga et al. (2005) observou que a elaboração de dietas que propiciem excelente dese mpenho e. consequentemente, reduzam os custos com produção são uma grande forma de minimizar os custos de produção.

As embalagens utilizadas no acondicionamento dos ovos também têm a sua importância representando $14,29 \%$ do COE, da mesma forma o produtor precisa procurar reduzir esses custos.

Tabela 2. Custo operacional total da produção de ovos caipiras, por ano, criadas em sistema semiextensivo, na região de llha Solteira - SP, 2011.

\begin{tabular}{l|l|l|l|l}
\hline DESCRIÇÃO & Unidade & Quantidade & $\begin{array}{l}\text { Valor } \\
\text { Unitário }\end{array}$ & Valor total (R\$) \\
\hline Ração & $\mathrm{kg}$ & 3.227 & 1,20 & $3.872,40$ \\
\hline Produtos veterinários & unid. & 4 & 2,00 & 8,00 \\
\hline Embalagens (ovos) & unid. & 225 & 2,90 & 652,50 \\
\hline Adubo verde (manutenção pasto) & $\mathrm{kg}$ & 150 & 0,22 & 33,00 \\
\hline Custo Operacional Efetivo (COE) & & & & $\mathbf{4 . 5 6 5 , 9 0}$ \\
\hline Outras despesas (5\% COE) & $5 \%$ & & & 228,30 \\
\hline Depreciação & & & & 100,00 \\
\hline Custo Operacional Total (COT) & & & & $\mathbf{4 . 8 9 4 , 2 0}$ \\
\hline
\end{tabular}

Uma alternativa seria realizar compras em conjunto, através de aquisições maiores, poderiam conseguir redução nos preços. Para isso precisam pertencer alguma organização de produtores, como cooperativas e/ou associação, que poderiam viabilizar estas compras.

Os resultados da Tabela 3 mostram que atividade é lucrativa, o lucro operacional foi de $R \$ 2.974,10 /$ ano considerando apenas - COE e um pouco menor de R\$2.665,80/ano para o COT. A receita bruta gerada pela produção de 2700 dúzias/ano a um preço médio obtido na região de $\mathrm{R} \$ 2,60 /$ dúzia e da diferença obtida na aquisição e na venda das aves após um ano de postura foi de $\mathrm{R} \$$ $7.540,00$ /ano. O preço de equilíbrio foi de $R \$$ $1,81 /$ dúzia, isto é, o preço mínimo a ser obtido para cobrir o custo operacional total em uma ảrea total de $100 \mathrm{~m}^{2}$. Os valores muito embora sejam positivos são baixos, mas o que deve ser ressaltado é que em média o produtor gasta $R \$ 407,85$ e recebe bruto $R \$ 628,33$. 0 resultado poderá ser mais viável economicamente se o produtor aumentar o número de aves e conseguir reduzir custos, sem se esquecer da outra ponta que é o comprador, as opções para comercializar a sua produção.

Há potencial para o crescimento da produção de ovos caipira para o pequeno produtor da região de llha solteira (SP), a demanda é grande, e o consumidor está interessado em qualidade, em consumir produtos mais saudáveis. A comercialização de ovos caipira em feiras livres da região (preço médio da dúzia $\mathrm{R} \$ 3,50$ ) se mostra como uma alternativa para obtenção de um maior valor do produto final. 
Tabela 3. Produção, preços e indicadores de lucratividade de galinhas caipiras criadas em sistema semiextensivo na região de llha Solteira - SP.

\begin{tabular}{|c|c|c|c|}
\hline Indicadores & Unidade & Valor (anual) & Valor (mensal) \\
\hline Produção & dúzia & 2.700 & 225,00 \\
\hline Descarte das aves & $\mathrm{R} \$$ & 520,00 & 43,33 \\
\hline Preços & $\mathrm{R} \$ /$ dúzia & 2,60 & 2,60 \\
\hline Receita bruta & $\mathrm{R} \$$ & $7.540,00$ & 628,33 \\
\hline Custo Operacional Efetivo & & $4.565,90$ & 380,49 \\
\hline Lucro operacional (COE) & & $2.974,10$ & 247,84 \\
\hline Índice de lucratividade (COE) & & $39,44 \%$ & $39,44 \%$ \\
\hline Custo Operacional Total & $\mathrm{R} \$$ & $4.894,20$ & 407,85 \\
\hline Lucro operacional (COT) & $\mathrm{R} \$$ & $2.645,80$ & 220,15 \\
\hline Índice de lucratividade (COT) & $\%$ & 35,1 & 35,1 \\
\hline Preço de equilíbrio & $\mathrm{R} \$$ /dúzia & 1,81 & 1,81 \\
\hline
\end{tabular}

\section{CONCLUSÃO}

Com base nos resultados apresentados pode-se concluir que a produção de ovos caipira no sistema semiextensivo é rentável. O produtor precisa de uma gestão eficiente em todo o sistema, principalmente na aquisição da ração, das embalagens e na comercialização dos ovos para lograr lucratividade maior. A produção vai servir como uma renda extra para o produtor e este deve busca formas de agregar valor ao ovo, por ser um produto diferenciado.

\section{REFERÊNCIAS BIBLIOGRÁFICAS}

AVISITE. Congresso da APA promove discussões sobre consumo comercialização do ovo. 2008. Disponivel $\mathrm{e} \quad \mathrm{m}$

<http://www.avisite.com.br/reportagem/report agem.asp?codigo $=89>$. Acesso em: $5 \mathrm{abr}$. 2011.

BARBOSA, F. J. V.; ARAÚJO NETO, R. B.; SOBREIRA, R. S.; SILVA, R. A.; GONZAGA, J. A. Seleção, acondicionamento e incubação de ovos caipiras. Teresina: Embrapa Meio Norte, 2004. (1 Fôlder)
BARBOSA, F. J. V. et al. Sistema Alternativo de Criação de Galinhas Caipiras. Disponível e $\mathrm{m}$

<http://sistemasdeproducao.cnptia.embrapa. br/FontesHTML/Ave/SistemaAlternativoCriac aoGalinhaCaipira>. Acesso em: 26 abr. 2011.

BRAGA, C. V. et al. Efeito da Inclusão do Farelo de Coco em Rações para Poedeiras Comerciais. Revista Brasileira Zootecnia, Fortaleza, v. 34, n. 1, p.76-80, 2005.

FIGUEIREDO, E. A. P.; AVILA, V. S.; ROSA, P. S.; JAENISCH, F. R. F. Cria e recria das poedeiras coloniais EMBRAPA 051. Informativo Técnico. Disponível em: <ht t p://pt.engormix.com/MA. avicultura/administracao/artigos/cria-recriapoedeiras-coloniais-t636/124-p0.htm>. Acesso em: 19 dez. 2011.

FIGUEIREDO, E. A. P.; AVILA, V. S.; ROSA, P. S.; JAENISCH, F. R. F. Embrapa 041, Frango de Corte Colonial. Informativo Técnico. 2006 . Disponivel em: <http://www.cnpsa.embrapa.br/sgc/sgc_publi cacoes/itav021.pdf>. Acesso em: 21 mai. 2014. 
GESSULLI, O. P. Avicultura alternativa. Porto Feliz: OPG. Editores Ltda. 1999, 218 p.

IBGE. Instituto Brasileiro de Geografia e Estatística. Abate de animais, produção de leite, couro e ovos. Disponivel em: <http://www.ibge.gov.br/home/estatistica/indi cadores/agropecuaria/producaoagropecuaria labate-leite-couro-ovos_201004 4.shtms. Acesso em: 18 jun. 2011.

LOT, L. R. T.; BROEK, L. V. D.; MONTEBELLO, P. C. B.; CARVALHO, T. B. Mercado de ovos: panorama do setor $e$ perspectivas. 2005. Disponivel em: <http://cepea.esalq.usp.br/pdf/Cepea_panor amaovos.pdf>. Acesso em: 31 ago. $201 \overline{4}$.

MAIA, G. A. R. Avicultura Alternativa: carne e ovos pelo sistema de pastejo. Disponivel e

$\mathrm{m}$

<http://www.ruralsoft.com.br/manejo/manejo Exibe.. sp? $i d=87 \# . U X 1 F d s q X S J o>$. Acesso em: 20 mai. 2014.

MARTIN, N. B. et al. Sistema integrado de custos agropecuários - CUSTAGRI. Informaçōes Econômicas, São Paulo, v. 28, n. 1, p.7-28, 1998.

MOREIRA, R. F. Avaliação nutricional de fenos utilizados na alimentação de poedeiras. 2008. 57 f. Dissertação (Mestrado em Zootecnia) - Universidade Federal do Ceará, Fortaleza , 2008.

SAGRILO, E. (Ed.). Agricultura familiar. Teresina: Embrapa Meio-Norte, 2002. 74 p. (Embrapa Meio-Norte. Sistemas de produção, 1). 